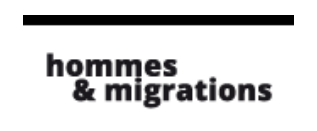

Hommes \& migrations

Revue française de référence sur les dynamiques

migratoires

1286-1287 | 2010

Les migrations subsahariennes

\title{
Devenir français et rester russe
}

L'itinéraire de Nicolas et Adèle Vorontzoff

\section{Fabrice Grognet}

\section{(2) OpenEdition \\ 1 Journals}

\section{Édition électronique}

URL : http://journals.openedition.org/hommesmigrations/1669

DOI : 10.4000/hommesmigrations.1669

ISSN : 2262-3353

Éditeur

Musée national de l'histoire de l'immigration

\section{Édition imprimée}

Date de publication : 1 juillet 2010

Pagination : 280-285

ISSN : 1142-852X

\section{Référence électronique}

Fabrice Grognet, «Devenir français et rester russe », Hommes \& migrations [En ligne], 1286-1287 |

2010, mis en ligne le 29 mai 2013, consulté le 22 septembre 2020. URL : http://

journals.openedition.org/hommesmigrations/1669; DOI : https://doi.org/10.4000/

hommesmigrations. 1669

Ce document a été généré automatiquement le 22 septembre 2020.

Tous droits réservés 


\title{
Devenir français et rester russe
}

\author{
L'itinéraire de Nicolas et Adèle Vorontzoff \\ Fabrice Grognet
}

\section{De Rostov-sur-le-Don à Paris : un parcours conditionné par l'Histoire}

1 “Mon père est né à Kiev - en Russie à l'époque - le 13 janvier 1904. Il était issu d'une famille de militaires depuis plusieurs générations. Ainsi, mon grand-père, Théodore, était général. Mon père suivait donc cette tradition familiale.

2 Seulement, suite à la révolution bolchevik, l'école des 'Cadets du Don', à Rostov-sur-le-Don, école pour officiers où se trouvait mon père, a été évacuée par les Anglais à Ismailia, près du Canal de Suez. Ce qui a fait qu'il a terminé ses études secondaires et militaires dans cette école, en Égypte, où il est resté jusqu'au début des années vingt. Ensuite, il fallait bien chercher un pays d'asile. Il est alors parti en Bulgarie ${ }^{1}$, où il a fait une année d'étude militaire - bien que l'armée russe n'existait plus - pour être promu 'aspirant', je crois."

3 "Par la suite, il a cherché à partir quelque part. Étant donné qu'il avait de bonnes notions de français - on parlait déjà un peu le français dans la famille et également à l'école militaire - et que d'autres Russes lui avait conseillé de venir, il est parti en France en 1923; un pays où se développait l'industrie, ce qui a aussi attiré mon père. Et puis il savait qu'il n'allait pas être seul en France, qu'il y avait beaucoup de Russes qui avaient déjà fait ce choix avant lui ${ }^{2}$ ".

4 L'industrie française à en effet besoin d'une main-d'œuvre devenue rare dans le contexte de l'après-Première Guerre mondiale. Des recruteurs, en quête d'hommes jeunes et en bonne santé, sillonnent alors les pays d'accueil (Bulgarie et Yougoslavie ${ }^{3}$ notamment) des réfugiés russes.

5 “À vrai dire, à cette époque, mon père n'avait aucun métier. Il a commencé à travailler comme manœuvre dans différentes entreprises françaises, pour Panhard et Levassor notamment. Et après avoir travaillé quelques années, il a appris à conduire. Mon père est alors devenu chauffeur de taxi, comme beaucoup de Russes qui lui avait d'ailleurs conseillé de faire comme eux. Il travaillait de nuit, car les gains étaient meilleurs et les pourboires plus intéressants. Les revenus étaient irréguliers, mais il était plus libre, selon lui." 
Pour Nicolas Vorontzoff (1904-1979), sans qualification autre que militaire, devenir "cocher et chauffeur" de taxi à la fameuse "G7", Compagnie française des Automobiles de place en 1925, représente en effet une alternative à l'usine et à ses contremaîtres. Polyglottes, perçus comme "bien élevés" par la majorité des Français ${ }^{5}$, les immigrés russes - le plus souvent amalgamés aux "Russes blancs" - sont alors prisés par les entreprises de taxis parisiens. Mais surtout, dans la société russe en exil et reconstituée à Paris - devenue "capitale de la diaspora russe"-, les réseaux des immigrés russes s'organisent et la solidarité opère. Habitant une location meublée au 11,rue Fondary dans le $\mathrm{XV}^{\mathrm{e}}$ arrondissement, un des lieux majeurs de l'installation russe à Paris ${ }^{7}$, Nicolas exerce ainsi la profession de chauffeur de taxi, encouragé par l'expérience de ses compatriotes aillant vécu le même parcours. "Pour arrondir ses fins de mois, mon père faisait aussi de la photo. Il trouvait chez des Russes des gravures ou des photographies qui avaient été faites avant la Révolution. Il en faisait des contre-types qu'il arrivait à vendre parmi ses compatriotes en exil, nostalgiques de la Russie d'autrefois. Car il y avait une colonie russe très importante à l'époque. Il y avait un théâtre russe, des restaurants, des boîtes de nuit russes. Et c'est dans cette colonie reconstituée en plein Paris que mon père a rencontré ma mère, Adèle Reznikoff, russe elle aussi."

\section{Faire sa vie dans la capitale de la diaspora russe}

7 Originaires de la région de Smolensk, les Reznikoff, anciens propriétaires terriens ayant dû quitter eux aussi la Russie, arrivent en France en 1922 après avoir transité par Constantinople - sous contrôle Alliés - pendant deux ans'. Dans un premier temps, ils rejoignent en Côte-d'Or le grand-oncle ${ }^{10}$ d'Alexis, marié à une Française. Mais, sans revenus, les grands-parents d'Alexis décident de partir pour Paris: "Pour le village, c'était un événement. Les seules personnes qui n'avaient jamais vu Paris, c'étaient les quelques anciens militaires de la guerre 14-18. Étant paysans, les villageois n'avaient aucun moyen de voyager vers la capitale."

8 À Paris, la vie des Reznikoff n'est pas simple. Mais, là encore, les réseaux des immigrés russes en exil permettent de faire face : "Mon grand-père, Constantin, qui était déjà âgé et qui parlait très mal le français, avait beaucoup de difficulté à trouver un emploi. Son titre officiel était 'garçon de bureau' dans un tas de sociétés de cinéma. En fait, il portait les paquets, les boites de films, etc."

9 Constantin trouve son premier emploi dans la société de production "Albatros", créée en 1922 par Alexandre Kamenka (1888-1969). Installée à Montreuil, elle privilégie en effet l'emploi de Russes immigrés en France, tout en cédant, dans un premier temps, aux productions liées à la mode orientaliste du mythe de l'âme slave" qui séduit alors la "bonne société" parisienne.

"Ma grand-mère, quant à elle, travaillait comme couturière à domicile, avec une clientèle À $90 \%$ russe. Autrefois, en Russie, elle avait une couturière qui venait une fois par semaine chez elle. Mais une fois arrivée à Constantinople, elle a dû trouver une activité. Elle a alors acheté une machine à coudre, celle-là même qu'elle a rapporté en France, car elle ne connaissait finalement qu'un seul métier: celui de couturière." Les Reznikoff, à l'image de leurs compatriotes réfugiés, profitent ainsi des réseaux organisés au sein de la communauté russe de Paris qui génère les emplois - tant masculins que féminins - nécessaires à son propre fonctionnement. 
11 “Ma mère n'a jamais eu d'emploi stable. À un moment donné, elle faisait un peu de mannequinat dans des maisons de confection ${ }^{11}$. Et puis elle a rencontré mon père. Ils se sont mariés en 1926 et je suis né un an plus tard. Mais quand mes parents m'ont eu, ils étaient très jeunes. Ils ont demandé à ma grand-mère maternelle: 'on est jeune, on voudrait un peu s'amuser, sortir, on a des copains, est-ce que tu ne pourrais pas t'occuper d'Alexis?'. Grand-mère avait posé comme condition qu'elle prenne mon éducation en main et qu'elle s'occupe de moi jusqu'à la fin de mes études. C'est elle qui a désiré que j'aille dans une école secondaire russe, à Boulogne. Et jusqu'à l'âge de 6 ans, je n'ai parlé que le russe. Mon père et ma grand-mère n'étaient pas d'accord sur la façon de mener mon éducation et les choses sont restées relativement tendues. À un moment donné, nous habitions tous dans un immeuble dans le $X V^{e}$ arrondissement, au 10, rue Mademoiselle. Mes grands-parents étaient au deuxième étage et mes parents au cinquième. Mais moi, j'allais rarement chez eux, l'on se croisait quelques fois dans l'escalier."

12 Avec l'éducation d'Alexis, où l'apprentissage du russe semble primordial, on devine l'envie de sa grand-mère de transmettre une "identité russe" à son petit-fils, né en exil à Paris. Nicolas, quant à lui, espérait peut-être avant tout pour son fils une intégration dans la société d'accueil qui l'avait vu naître, sans espoir d'un retour vers une Russie devenue soviétique depuis $1922^{12}$ ? Toujours est-il qu'en plus d'une “éducation à la russe", ses grands-parents lui ont transmis un goût pour le cinéma qu'ils n'avaient sans doute pas anticipé: “Mon grand-père s'était lié avec Fédor Bourgassoff, un chef opérateur réputé. Il y avait une caméra installée dans l'entrée de l'appartement des Bourgassoff, rue de Vaugirard. Et c'est à leur contact qu'est née ma passion pour le cinéma ${ }^{13}$."

\section{Cesser d'être apatride pour devenir français}

13 "Mes parents étaient à l'époque considérés comme réfugiés russes ${ }^{14}$. Ils possédaient un passeport Nansen ${ }^{15}$, que mon père - et les Russes d'une manière générale - appelaient 'garmochka' [accordéon] - en raison des nombreux volets qu'il fallait déplier.

Mais il y avait une loi, votée après les années de la Première Guerre mondiale, qui stipulait qu'en cas de nouvelle guerre, les réfugiés pouvaient être susceptibles d'être incorporés à l'armée française ${ }^{16}$. Mon père a donc été mobilisé en septembre 1939 - comme beaucoup de ses anciens copains de l'école militaire - et il a été envoyé au $311^{e}$ régiment d'artillerie de Rennes. Ce régiment était aux trois quart composé de Bretons. Et d'après ce qu'il m'avait dit, mon père parlait finalement mieux le français que la plupart de ses camarades de régiment qui, entre eux, parlaient le breton [...]. Une fois démobilisé, en août 1940, mon père est alors revenu sur Paris et a fait de petits métiers. [...] À la Libération, étant donné qu'il parlait anglais pour l'avoir appris à Ismailia, vingt ans auparavant, il a trouvé un emploi de chauffeur dans différents organismes américains, notamment à l'Ambassade américaine de Paris. Comme il était mieux payé, il a donc arrêté d'être chauffeur de taxi."

15 C'est aussi après-guerre que Nicolas Vorontzoff - apatride comme tous les autres réfugiés russes - décide de demander la nationalité française. Seulement, "il s'est entendu répondre par les autorités administratives françaises qu'il fallait attendre ma majorité, si je choisissais alors d'opter pour la nationalité française, sa demande de naturalisation serait facilitée. Parce que j'étais réfugié russe, ce qui posait d'énormes problèmes. Quand je remplissais des papiers, notamment pour mes études, je mettais comme lieu de naissance: 'Paris' et pour la nationalité : 'réfugié russe'. Tout le monde se moquait de moi, se demandant comment je pouvais être réfugié russe en étant né à Paris?. Alors je leur disais que c'était la loi française qui était comme ça... À ma majorité, j'ai donc choisi la nationalité française, car je pouvais aussi rester 
réfugié russe. Et parmi les papiers de mon père, il y a un numéro du Journal officiel où est inscrite notre naturalisation."

En 1948, la famille Vorontzoff devient ainsi française. Un an plus tôt, à l'image de nombreux autres Russes citadins voulant retrouver l'esprit de la datcha d'autrefois, Nicolas et Adèle achètent un bout de cette terre française qui va désormais être la leur : "Avec l'aide d'un ami d'enfance, mon père a construit de ses mains une petite maison au Perray, dans les Yvelines. À l'époque c'était possible de le faire sans permis de construire. C'était leur maison de campagne."

Et, à la fin de leur vie, Nicolas et Adèle renouent avec leur identité russe : Nicolas est enterré au fameux cimetière russe de Sainte-Geneviève-des-Bois ${ }^{17}$ tandis qu'Adèle intègre la maison de retraite de la "Croix-Rouge russe ${ }^{18 ", ~ a ̀ ~ C h e l l e s, ~ o u ̀ ~ e l l e ~ f i n i r a ~ s e s ~}$ jours. L'itinéraire de Nicolas et Adèle Vorontzoff croise ainsi le destin de milliers de leurs compatriotes exilés à Paris et oscille finalement entre la nécessité de refaire sa vie en France et le désir de conserver leur identité originelle.

\section{NOTES}

1. Libérée de la tutelle ottomane par l'armée russe à la fin du XIX ${ }^{\mathrm{e}}$ siècle, la Bulgarie accueille près de 4000 réfugiés militaires et civils russes.

2. Dès la fin du XIX ${ }^{e}$ siècle, une petite communauté d'aristocrates et d'intellectuels russes est installée en France. Dans les années vingt un million et demi de "Russes blancs" quittent la Russie. Politique avant tout, cette émigration est également déterminée par les bouleversements économiques consécutifs à la Première Guerre mondiale et à la guerre civile. 400000 personnes gagnent ainsi la France, chassées de leurs premiers pays d'accueil, notamment l'Allemagne et la Turquie. Les officiers issus de la noblesse ou les soldats d'origine paysanne constituent alors la part la plus importante de la population immigrée.

3. À l'époque nommée Royaume des Serbes, Croates et Slovènes.

4. Seul l'arrière des véhicules possédait un toit pour les passagers, à la manière des fiacres de l'ancien temps.

5. Dans Les Ritals (1973), François Cavanna revient sur l'image des Russes à cette époque : "Il y a bien aussi les Russes, mais les Russes c'est pas des étrangers. Ils font des métiers de Français. Les Français ne les méprisent pas, ne se foutent pas de leur gueule à l'école. C'est eux qui méprisent les Français. Il paraît que c'est tous des princes et des marquises et qu'ils se sont sauvés à cause des bolcheviks qui tuaient tous les aristocrates. Les Français ne les aiment pas beaucoup, les Français n'aiment personne, mais on sent qu'ils ont de la considération parce que c'est pas des vrais pauvres mais des gens riches qui ont vécu des choses très tristes, comme dans les feuilletons."

6. À cette époque, près de 45000 Russes sont recensés en région parisienne.

7. À cette époque, près de 45000 Russes sont recensés en région parisienne.

8. Née à Moscou le 4 janvier 1907 et décédée à Chelles en 1988.

9. Adèle Reznikoff, après avoir séjourné dans un lycée russe en Tchécoslovaquie, rejoint ses parents lorsqu'ils s'installent à Paris.

10. Ce grand-oncle partira plus tard à Meudon - "Meudonsk" réapproprié en russe - en banlieue parisienne. 
11. Comme ce fut le cas pour de nombreuses jeunes femmes de l'émigration russe ?; voir Andreï Korliakov, Émigration russe France 1917-1947. Honneur et dignité maintenus, Paris, YMCA-Presse, 2001. 12. Le nouveau régime soviétique révoque, par décret du 15 décembre 1922, la nationalité de tous les émigrés russes.

13. Alexis Vorontzoff a exercé la profession de caméraman, notamment pour le service audiovisuel de l'Unesco.

14. Voir Catherine Goussef, L'Exil russe, 1920-1939. La fabrique du réfugié apatride, Paris CNRS, 2008.

15. Créé en 1922, à l'initiative de Fridtjof Nansen (1861-1930), premier Haut-Commissaire pour les réfugiés de la Société des Nations, ce document établit un nouveau statut pour les réfugiés devenus apatrides.

16. La Société des Nations ayant admis que les apatrides pouvaient être mobilisés au profit du pays dans lequel ils résidaient le jour de la déclaration de la guerre, la loi française du 31 mars 1928 a inclus cette clause dans son article 3.

17. Le cimetière russe de Sainte-Geneviève-des-Bois est lié à la fondation de la "Maison Russe" (lieu de refuge pour les "Russes blancs" créé en 1927 par la princesse Vera Mestchersky à qui une Anglaise, Miss Dorothy Paget, offre le château de la Cossonerie). Les sépultures des premiers pensionnaires de la Maison Russe reposent dans l'ancien cimetière communal. Ce dernier s'ouvre par la suite aux personnes d'origine russe décédées en région parisienne, mais aussi en province, voire à l'étranger. À ce jour, environ 10000 personnes y reposent, faisant de ce lieu la plus grande nécropole russe en dehors de Russie.

18. Originellement, la maison, achetée par la Princesse Gagarine, héberge des invalides de guerre russes. À partir de 1938, elle est reprise par la Croix-Rouge russe puis deviendra une maison de retraite ouverte à tous.

\section{RÉSUMÉS}

Après avoir appris l'ouverture de la Cité nationale de l'histoire de l'immigration, Alexis Vorontzoff se rend à la Porte Dorée en novembre 2007. À la suite de sa visite, il décide de rechercher différents documents et objets qui permettraient d'évoquer le parcours de ses parents - Nicolas et Adèle - réfugiés russes venus s'installer dans le Paris des années vingt: "Je n'ai pas d'enfant et ma filleule n'a pas connu mes parents. Elle ne s'intéresse pas trop à ces histoires et comme j'avance en âge, j'aimerais que tout cela ne disparaisse pas complètement avec moi."

\section{AUTEUR}

\section{FABRICE GROGNET}

Ethnologue, chargé de mission au Musée national de l'histoire et des cultures de l'immigration, CNHI. 